\title{
Reflections on the Development and Inheritance of the Dai Music Culture
}

\author{
Wenmin Zhong \\ School of Music and Dance \\ Qujing Normal University \\ Qujing, China 655011
}

\begin{abstract}
In the multi-social background factors, we can see the development course of modern civilization in the development of the Dai music culture. Modern civilization has played a certain role in the development and inheritance of the Dai culture from different levels and different aspects. The Dai nationality is a multinational people with a small population, and there are differences in the Dai music culture in different countries and regions. They have their own customs and habits, and they also have their own unique music culture. But in recent years, it now faces many problems, such as, the passaway of inheritors, less attention of local government, lack of industrial development and weak protection awareness to its cultural heritage, which seriously restrict the inheritance and development of Dai music culture. But with the national emphasis on intangible cultural heritage protection and inheritance, various local governments enhance the protection of the intangible cultural heritage. In order to discuss the protection of the intangible cultural heritage, the author has carried out a research on the Dai music culture in a realistic manner with the methods of the combination of literature and investigation, and analyzed it from various angles. The author also puts forward some countermeasures and suggestions to solve the problems in the protection and inheritance of the intangible cultural heritage.
\end{abstract}

Keywords-Dai music; music culture; protection countermeasures

\section{INTRODUCTION}

With the state's attention to the protection and inheritance of the intangible cultural heritage, local governments all over the country have enhanced the protection of the intangible cultural heritage. The intangible cultural heritage is changeable, non-renewable and instable due to its non-material, oral and performing characteristics. To a great extent, it highlights the value of the intangible cultural heritage. The Dai music culture is an important part of Chinese intangible cultural heritage, same as other favorable intangible cultural heritages. Dai folk songs, as a kind of intangible cultural heritage, are non-material and unstable and can be passed down. Under the current conditions, accompanied by the emergence of some new forms of music, it is so difficult to inherit and protect the Dai folk songs. So far, our country attaches little importance to Dai music culture, and doesn't dig the connotation in the Dai music culture. It is extremely unfavorable to the inheritance and development of Dai music culture if we cannot understand the spirits in it.

\section{THE TYPES AND CHARACTERISTICS OF DAI MUSIC}

Dai nationality is a unique ethnic group in Yunnan. They mainly live in the Xishuangbanna Dai Autonomous Prefecture, Dehong Dai and Jingpo Autonomous Prefecture and Gengma Lincang Dai and Wa Autonomous Prefecture and some other regions in Yunnan Province. According to statistics in 2015, the population size of the Dai people in Yunnan has reached 2560000, accounting for $8.59 \%$ of the total number of ethnic minorities in the province. Dai people can sing and dance, and they have various kinds of music culture, including folk songs, narrative songs, love songs and labor songs. It can be discussed specifically from the following four aspects.

\section{A. Folk Song}

Dai folk song is the main type of Dai music. Generally, young people sing solely or one to another in the fields or hills. Dai folk songs are melodious, lyrical and moving, and the lyrics are very poetic. Most songs are used to praise nature, to sing the harvest or love. Each song is improvised, free of restrictions, and can be short or long, high or low. Singers can sing a song with defined keynotes and end but free and different tune and melody according to the tone and the number of syllables. Due to their different languages, there are various types of folk songs in Dai people's regions. People in different regions give folk songs different names. So, the types of Dai folk song are named according to its location, such as, "Han Ma Zhe Fang" and "Han Ma Meng La". Dai folk song is a form of music culture composed by Dai labor people in the process of production. There are some popular folk songs, such as "We Never Separate", "Shout", "You Look Like Blossoming Flowers" and so on.

\section{B. Narrative Song}

Narrative song of Dai people is called as Ganpai in their slang. On the content, it generally can be divided into three types, including mythic narrative song, heroic narrative song and love-tragedy narrative song. These types of songs are popular in Dehong and Xishuangbanna. In the Mangshi City and Ruili of Dehong, there are special Han show, Hanwuwo and Hannuanwo. Except for Menglian and some other 
regions, most of them are without music accompaniment. Most of the narrative songs don't need accompaniment, and singers sing them without makeup. In Xishuangbanna, the most representative narrative songs are "Sang Hong Diao" and Hongde's "Ying Wu Diao". Narrative songs are widely spread in Dai settlements, forming different types and tunes. In different settlements, people sing same song with difference styles and tunes.

\section{Love Song}

When a young man falls in love with a young woman they sing love songs to express his affection. Dai people like wear cloth clothes, so they often sing love songs to each other after work at night when they are in love. Under such conditions, the love song becomes an important mean for them to express love. Or perhaps they sing love songs in the outer fields. However, love song in Dehong is quite different from other regions, because young people there are good at playing musical instruments. They like singing and playing to show their affection and miss to their beloved in a crooning way with a melodious style, such as "Love Song" in Xishuangbanna Jinghong County, "Beautiful Zhanjia Flower" in Ruili and "Wa Shao" in Jinping Mengla.

\section{Labor Song}

Dai people call labor song Ganha Heishang which they mainly sing in their work. Han people's labor chant refers to the song with strong beat that is coordinated with labor actions to facilitate working. Both of them have a long history. Dai people's labor song has strong beat and relatively narrow range, short and simple lyrics. It is used to uniform working rhythm, enhance work effect and improve work efficiency. In the development of Dai society, rich labor contents create colorful types of labor songs, mainly including rice-transplanting song, harvest song, woodcarrying song and water-fetching song.

\section{THE PROBLEMS EXISTING IN THE INHERITANCE OF THE DAI MUSIC CULTURE}

Music education and music inheritance are two important aspects in the music development, and they are closely related and influenced each other. Due to the lack of corresponding media in the Dai music culture, Dai people pass it by word of mouth from generation to generation. We should gradually achieve the inheritance of these ethnic musical culture based on their living habits, folks and customs. According to current situation, there are four problems in the inheritance of Dai music culture.

\section{A. The Pass-Away of Inheritors Making It Hard to Sustain}

The protection of the traditional music of ethnic minorities is imperative. In the process of inheritance and protection, the most important problem encountered is the successive pass-away of the inheritors making it hard to sustain. With the passing of the older inheritors, many skills are faced with the possibility of losing inheritance because they are handed down by older artists. Culture is mainly from the folk and some folk inheritors, and handed down from generation to generation. In the earlier period, these artists learned skills in order to make a living. With the passage of time, it is hard for them to support family only by relying on these traditional skills, especially in today's rapid development society. So, they had to give up traditional skills and turn to engage in other industries. It loses the most basic conditions to inherit them. In the face of the current situation, many Dai young people don't want to put into the traditional artistry. Thus, many traditional and excellent skills are without inheritor and lack support. Even some of skills are up against disappearing. And so is Dai traditional music culture. There are only a few old artists like Bo Yefa. Young people who are willing to learn traditional Dai music and instruments become less and less. The main problem facing traditional skills is the lack of inheritors, so that these traditional skills may be lost at any time.

\section{B. The Remote Areas with Inadequate Attention}

With the rapid development of society, the living standards and social undertakings of the Dai people have improved significantly. The music culture also has a great development. Dai music comes from the folk, and is also spread among the folk. But it is undeniable that still a lot of music culture contents are not known by the public. Only a few groups know it. Many traditional music culture contents are not known by the public, resulting that it is not well protected and passed down. For example, the traditional Dai music is only popular among the local and surrounding villages. Out of these villages, it cannot survive. These areas are remote, and the traditional music culture is only popular in the local places and known by the local people. And it is closely related to local living habits and customs, so it is much difficult for the music culture with local characteristics to get known by the public. Currently our state gave a lot of policies to support the inheritance of intangible culture heritage. But still some small places don't attach importance to the traditional artistry. These places usually are remote and unknown, or even don't get the attention of the government. These traditional music skills finally will fade out of people's lives, especially when they cannot bring corresponding benefits. Then they will disappear slowly.

\section{THE COUNTERMEASURES TO PROTECT AND INHERIT THE DAI Music CULTURE}

\section{A. Strengthening the Music Education Ability of Ethnic Minorities}

As a music teacher in the future, it is the basic premise to strengthen the music education of minorities to strengthen the national music accomplishment. It is very important to improve the music teaching ability of music teachers in order to achieve good results. We shall have a passion for folk music, be familiar with folk music, have a certain theoretical knowledge of folk music and a higher ability in the implementation of national music education, and develop a passion and a strong sense of mission in the education of national music, so that we can ensure the high quality of our national music education and promote the healthy development of national music education. The school is the 
main front to carry forward the folk music, and the school should adjust the courses and teaching materials, organize school teachers to attend regular training to improve their national musical literacy. Set up a minority music education group and establish minority music teaching websites. Teachers should actively participate in music education research, academic research and special reports. Music teachers should also be the leader of this work. They should teach folk music knowledge in the course of teaching, and help edify students' sentiments and strengthen their national consciousness. At the same time, they should cultivate diversified qualities of music teachers in ethnic areas and set up diversified educational concepts. In the teaching practice, they can combine the local music culture. They can ask students appreciate and listen to the songs and their composition background, and imitate the scene to help students deeply understand the connotation and emotions of songs. Music teachers should regularly collect folk songs and take students if possible. And school can invite folk musicians with rich experience to assist teachers in teaching.

\section{B. Strengthening Legislative Protection}

The intangible cultural heritage and intangible cultural heritage are of equal importance. They are precious wealth and treasure left by our ancestors, conveying and continuing our spiritual blood and embodying our thinking of culture, values, aesthetic pursuit and emotional memory. So, we should further strengthen the protection of legislation. Current Dai music, as a non-material cultural heritage, has encountered many problems in the inheritance process. It has been urgent to protect Dai music culture. Related legislation is imperative. Now China already has relevant provisions on behalf of the rights and interests of inheritors of the intangible cultural heritages. These provisions have been implemented in various places, which have achieved certain results in the protection of inheritors of non-material cultural heritages. It should further clarify the interests and rights of inheritors and their obligations to strengthen legislative protection, so that we can protect inheritors of intangible cultural heritages and encourage more people to participate in the protection of our culture heritages. Thus, realize the effective transmission of Dai music culture.

\section{Raising the Government's Attention}

As the local governments are facing different intangible cultural heritages, the Dai People's music culture is also different. In different regions, they have different forms of music transmission. So, local governments should treat the inheritance and protection of cultural heritage differently according to the regional situations. National music is an important component of national culture. Therefore, the music departments in universities for minorities have an inescapable responsibility and obligation for the inheritance and development of national music culture. Many traditional Dai music cultures are well-known intangible heritage cultures. Enterprises and individuals can participate in the protection and inheritance. Like the peacock dance and folk songs, these cultures are known by the public, and there are many special lovers. So, a series of preferential terms can be put forward to attract their lovers to participate in the culture protection. However, due to the remoteness of the Dai people as well as their culture of music, only a few people know and love these traditional skills. Therefore, the local government can give more attention to the comprehensive and effective protection of the intangible culture heritages. The protection workers of intangible cultural heritage can go to remote places to help local inheritors pass down Dai traditional music culture.

\section{CONCLUSION}

In a word, the protection of intangible cultural heritages involves a wide range of work. To do it well, we shall not only play the government's function of protection but also get the opinion support of the public. Above all, we shall do our effort to protect Dai music culture from all around in order to pass down and develop the art value of traditional music culture.

\section{REFERENCES}

[1] Beng Xiaoyun. Arts of Dai People. Yunnan Arts University, 2012.

[2] Gui Xingxing. Study on the Productive Protection of Dai Brocade Skill in the Manwendian Village. Minzu University of China, 2012.

[3] Jin Lifen, Huang Qinglin. Dai People and Their Music Culture. National Music, 2009, (04): 45-47.

[4] Wang Xiaotao. Study on Regional Folk Song Teaching. Hebei Normal University, 2014.

[5] Fan Zuyin. Han People's Multi-part Folk Music Art. 1988 (01): 26$31+63$.

[6] Yang Li. A Study of Dai's Yi La Hui. National Art. 1991, (04): 158164.

[7] Wang Song. Dai People's Long Poem and Zan Ha. Ideological Front. 1980, (03): 89-93.

[8] Jiang Wenyuan. Research on Aka People's Music Behavior in Xishuangbanna. Yunnan Arts University, 2016.

[9] Jin Xin. Interrelation and Interplay of Music Inheritance and Music Education. Central Conservatory of Music, 2013. 